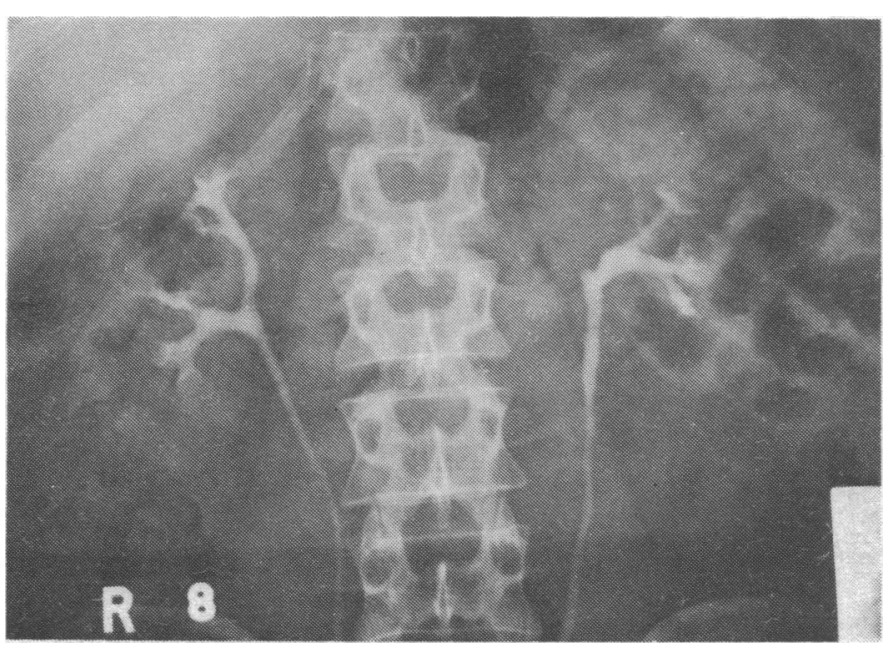

FIG. 2-Case 4. Intravenous pyelogram-early film showing delay in filling left upper calix. Apparently normal right kidney.

Pugh) showed a grossly dilated upper pole calix containing chalky material; microscopically the dilated calix was lined by tuberculous granulation tissue which in many areas had undergone organization and hyalinization. Though no acid-fast bacilli were seen the appearances were entirely consistent with the diagnosis of partially healed renal tuberculosis. He was started on standard triple drug therapy four months after first presenting, and in the subsequent 18 months has had no further attacks of pain in either kidney.

\section{Discussion}

Severe renal pain is usually said to be uncommon as a presenting symptom of renal tuberculosis, normally being associated in the more advanced cases with haematuria, the passage of tuberculous debris, or ureteric strictures (Wells, 1943; Freshman, 1962).

All our four cases presented with severe unilateral renal pain not associated with other urinary symptoms, though two had haematuria at some stage in the disease. The diagnosis of tuberculosis was not considered when they first presented because of the absence of "typical" symptoms of tuberculous disease and the absence of pyuria in all the patients. The initial pyelograms suggested tuberculosis in two patients but were normal in the other two. Case 4 was of particular interest in that he presented with right renal colic and was found on pyelography to have advanced left-sided renal tuberculosis with an apparently normal right kidney. After starting antituberculous therapy his pain disappeared completely, and was therefore presumably due to tuberculous involvement of the contralateral kidney. The renal pains have not returned in any of the four patients after starting standard drug therapy.

Tuberculosis is known as a great imitator. Wechsler et al. (1960) recommended a high index of suspicion regarding patients with vague renal colic, finding an incidence of $8 \%$ of new cases presenting with renal pain. In some larger series 4.6\% (Borthwick, 1956) and 9\% (Obrant 1955) of cases presented with pain as a main symptom. Nicholls (1953) went further and said that a parade of victims of the disease would present as an assortment of healthy-looking men and women.

Our purpose in reporting these cases is to encourage the search for genitourinary tuberculosis in all patients presenting with renal pain in whom a definite alternative diagnosis cannot be made. Emergency pyelography has reduced the number of cases presenting with renal pain being clinically diagnosed as "gravel" in which no radiological abnormality is found. Repeated urine culture for tuberculosis in these cases may further reduce their number.

We are grateful to Dr. R. C. B. Pugh for the histological report on Case 4.

\section{References}

Borthwick, W. M. (1956). Tubercle, 37, 120.

Freshman, E. (1962). Proceedings of the Royal Society of Medicine, 55, 968. Nicholls, M. F. (1953). In Modern Trends in Urology, ed. E. W. Riches, p. 357. London, Butterworth.

Obrant, O. (1955). Acta Chirurgica Scandinavica, 110, 3.

Wechsler, H., Westfall, M., and Lattimer, J. K. (1960). Fournal of Urology $83,801$.

Wells, C. (1943). Postgraduate Medical Fournal, 19, 270.

\title{
Value of Re-examining X-ray Films of Outpatients Attending Accident Services
}

\author{
C. S. B. GALASKO, P. R. W. MONAHAN
}

\section{British Medical fournal, 1971, 1, 643-644}

\section{Summary}

$X$-ray films of 4,665 patients who had attended an accident service as outpatients were reviewed by the clinicians and reported on by the radiologist the next day.

In 20 cases the radiologist did not comment on bony injuries which had been diagnosed and treated by the accident service senior house officer. The radiologist, however, detected bony injuries which had been missed by the accident service senior house officer in 26 cases. In 10 cases injuries

Accident Service, Radcliffe Infirmary, Oxford

C. S. B. GALASKO, ch.M., F.R.c.s., Senior Registrar

P. R. W. MONAHAN, M.B., F.R.C.S., Senior Registrar (Current address : Nuffield Orthopaedic Centre, Oxford) which had not been detected at the original examination or by the radiologist were noted when the $x$-ray films were reviewed. On two occasions the fracture was missed at all three examinations.

The daily joint review of $x$-ray films by accident service officers and the radiologist seemed to increase the clinical and radiological acumen of the staff of the accident service.

\section{Introduction}

Most patients attending accident services or casualty departments have relatively minor injuries, which are usually dealt with by the senior house officer on duty. These injuries may occur at times when a radiologist's opinion of the $x$-ray films is not immediately available. The severer injuries are usually seen by a more senior member of the team and, if the patient 
is admitted, are reported on by a radiologist the same or the next day, and any lesion missed by the senior house officer should be detected at this stage. There is, however, no guarantee that every discrepancy between the radiologist's findings and the original diagnosis would be picked up when the $x$-ray report was entered in the patient's notes.

It was decided, as a check on the system, to review all the $x$-ray films of patients attending this accident service whose injuries did not require admission and to compare the findings with the original diagnosis and radiological report.

\section{Patients and Methods}

During the four month period 9 March to 9 July 19708,527 new patients were seen at the Accident Service, Radcliffe Infirmary. Of these, 1,123 were admitted, and 4,665 of the remainder had $x$-ray films taken. The latter group of patients were discharged home after treatment and their $x$-ray films were reviewed the next day. About 50 sets were reviewed each day. $X$-ray films taken during the weekend were reviewed on Monday morning.

\section{Results}

In 20 cases $(0.4 \%)$ lesions were seen on the $x$-ray film by the senior houseman on duty but were missed by the radiologist when reporting on the films. The types of injury are shown in Table $I$. The fractures of the transverse processes, olecranon, radius, carpus, pubic ramus, tibia, and fibula were linear and undisplaced. Some of the phalangeal, metacarpal, and metatarsal fractures had a minor degree of displacement.

In 26 cases $(0.6 \%)$ the injury was not diagnosed when the patients first presented but was noticed by the radiologist when reporting on the $x$-ray films. These injuries are listed in Table II. For many of the patients a plaster cast had been applied since a severe soft-tissue injury had been diagnosed and the fracture was splinted in the correct position. The two patients who had not been adequately treated were those with

TABLE I-Injuries Diagnosed when Patient was Originally Seen but not Reported by Radiologist

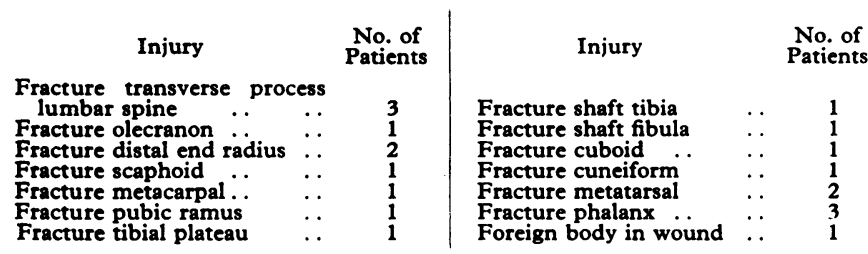
TABLE II-Injuries Diagnosed by Radiologist but Missed when Patient Presented
Initially

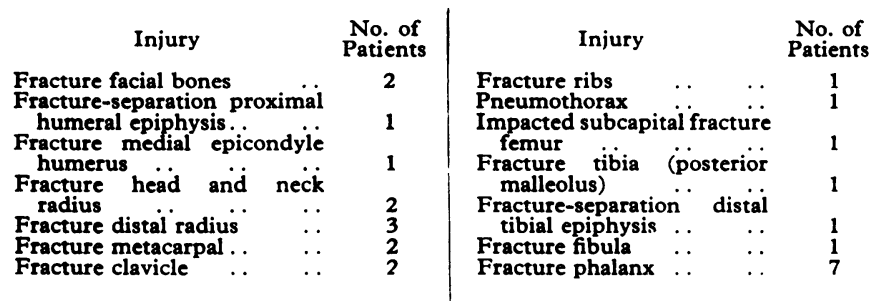

the pneumothorax and subcapital fracture of the femoral neck. The former returned to hospital complaining of dyspnoea before the $x$-ray films had been reported and a more severe pneumothorax was noticed on the film. The second patient was sent for when the $x$-ray films were reviewed. Neither patient developed any complication as a result of the 24-hour delay.
In 10 cases $(0.2 \%)$ (Table III) the injury was missed both by the clinician who first saw the patient and by the radiologist, but was noticed when the $x$-ray films were reviewed. In two cases the radiologist was a little suspicious and suggested that the films should be repeated if the symptoms persisted. The two patients with tears of the lateral collateral ligaments of their knee joints had widened lateral joint

TABLE III-Injuries Missed at Original Examination and by Radiologist but TABLE II-Injuries Missed at Original
Noted when X-ray Films were Reviewed

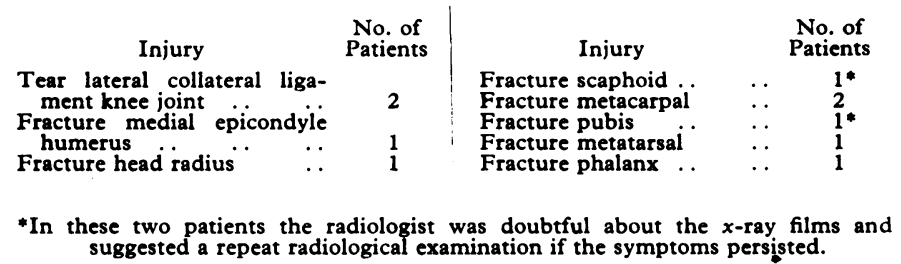

spaces on the original $x$-ray film. Stress films, taken subsequently, confirmed the diagnosis. In the other eight cases the correct treatment had been instituted empirically. The patient who had a fracture of his scaphoid had had a plaster cast applied because of clinical symptoms.

In only 2 of the 4,665 cases $(0.04 \%)$ were the injuries missed on the original examination and by the radiologist and at the review of the $x$-ray films. One was a fracture of the lateral malleolus and the other a fracture of the phalanx. Both the radiologist and the reviewers were suspicious of the talus in the patient with the undisplaced crack fracture of the malleolus, and the fracture was noted when the patient was recalled for a repeat examination. The fracture of the phalanx was noted some weeks later when the patient returned complaining of deformity and stiffness of the interphalangeal joint. Repeat $x$-ray films showed a fracture of the head of the proximal phalanx extending into the joint. Even in retrospect the original fracture was very difficult to detect.

\section{Discussion}

The results indicate that in a busy accident service very few fractures (less than $1 \%$ ) are missed by the senior house surgeon on duty. When the $x$-ray films were examined the next morning by the radiologist and the report was. carefully read when it was entered into the patient's case-notes this figure fell even lower. Nevertheless, some cases were misdiagnosed, but most of these injuries were detected when the $x$-ray films were reviewed by another member of the accident service. With increasing litigation this would appear to be important. Even this third check, however, is not infallible. It must be stressed, therefore, that even with the utmost care bony injuries can still be missed, and it is suggested that patients be asked to return if symptoms persist.

Most of the injuries that were missed occurred early on in the investigation and when a new senior house surgeon joined the unit. The daily review of $x$-ray films was held as a teaching session and all the injuries which had been missed originally were discussed. It is suggested that this was partially responsible for the increased clinical and radiological acumen that the staff developed during their six-month appointment, and that such a review of $x$-ray films should form an integral part of the teaching programme of an accident service.

We would like to thank Mr. J. C. Scott, Director of the Accident Service, Radcliffe Infirmary, and Dr. F. H. Kemp, Director of the Radiology Department, Radcliffe Infirmary, for their help and encouragement in carrying out this investigation. 